\title{
Sikap Toleransi Petani Padi Dan Tingkat Adopsi Teknologi Usahatani Padi
}

\author{
(The Tolerance Attitude of Rice Farmers and The Level of Technology Adoption \\ Rice Farming)
}

\author{
Andela Kristi Saragih ${ }^{1}$, Indra $^{1}$, Rahmaddiansyah $^{1 *}$ \\ ${ }^{1}$ Program Studi Agribisnis, Fakultas Pertanian, Universitas Syiah Kuala \\ *Corresponding author: rahmaddiansyiah@unsyiah.ac.id
}

\begin{abstract}
Abstrak. Padi adalah salah satu tanaman pangan jenis serealia yang banyak karbohidrat yang berfungsi sebagai sumber nutrisi. Toleransi merupakan sikap bersedia menerima keadaan yang sekarang tetapi dibarengi dengan berbagai standar penilaian. Perkembangan zaman menciptakan lima penerapan teknologi pertanian padi yang terdiri dari penerapan teknologi produksi dan pengolahan, penerapan teknologi peralatan, penerapan teknologi bangunan, penerapan teknologi lingkungan dan penerapan teknologi penanganan hasil panen. Sikap toleransi dan kelima Penerapan teknologi tersebut dapat meningkatkan hasil produksi panen padi dan menciptakan usahatani padi berkelanjutan dapat diukur dengan beberapa karakteristik responden berdasarkan umur, jenis kelamin, pendidikan. Tujuan dari penelitian ini adalah untuk mengetahui teknologi apa yang digunakan petani padi sawah di Kabupaten Aceh Besar dan Kabupaten Pidie Jaya, untuk mengetahui dan menganalisis bagaimana korelasi antara tingkat toleransi petani padi sawah dengan tingkat adopsi teknologi. Penelitian ini menggunakan metode deskriptif crosstabulasi menggunakan 60 sampel dengan teknik pengambilan quota sampling.

Berdasarkan data hasil penelitian, diperoleh teknologi-teknologi yang digunakan petani padi sawah di Kabupaten Aceh Besar dan Kabupaten Pidie Jaya adalah bibit unggul, teknik budidaya, pestisida nabati, pengendalian hama terpadu, traktor, rice transplanter, combine harvest, thresher, reaper, ITGM, sprayer, gasrok, sistem irigasi, embung, SRI, konvensional, rumah burung hantu, dan teknologi penggilingan. Diantara teknologi-teknologi tersebut, terdapat teknologi yang dominan dipakai oleh petani padi sawah yaitu: bibit unggul, traktor, sprayer, sistem irigasi, SRI, teknologi penggilingan. Tingkat toleransi dengan tingkat adopsi teknologi berkorelasi positif.
\end{abstract}

Kata kunci : Padi, Sikap toleransi, penerapan teknologi

Abstract. Rice is one of the many carbohydrates of the cereals that serve as a source of nutrition. Tolerance is a willingness to accept present circumstances but is coupled with a variety of standards of judgment. Current developments create five applications of rice farming technology consisting of the application of production and processing technologies, the application of equipment technologies, the application of building technologies, the implementation of environmental technologies and the application of crop treatments technologies. Tolerance and all five applications of the technology can increase the production of rice crops and create a sustainable market of rice could be measured by some of the characteristics of respondents by age, gender, education. The purpose of this study is to know what technology rice farmers use in both the great day and pidie jaya districts, to know and analyze how a correlation is between the level of rice farmers' tolerance and the level of technological adoption. The study USES a descriptive crosstabulation method using 60 samples with a sampling sampling technique. Based on research data, the technologies used by rice farmers in rice fields in aceh and jaya districts are superior seeds, agricultural techniques, vegetable pesticides, integrated pest control, tractors, rice transplanters, threshers, reaper, itgm, sprayer, gasrok, irrigation systems, sri, conventional, house of the owlery, and the mill technology. Among these technologies is the dominant technology for rice farmers: superior seeds, tractors, sprayer, irrigation systems, sri, mill technology. Tolerance levels with a highly correlated technological adoption rate.

Keyword: Paddy,Tolerance attitude, technology application, quota sampling

\section{PENDAHULUAN}

Padi adalah salah satu tanaman pangan jenis serealia yang banyak karbohidrat yang berfungsi sebagai sumber nutrisi bagi tubuh manusia. Muncul pula suatu istilah dikalangan penduduk Indonesia yang berkata "tidak makan kalau tidak makan nasi" artinya tidak 
kenyang kalau tidak makan nasi. Berdasarkan Badan Pusat Statistik Aceh (2020), Kabupaten Aceh Besar dan Kabupaten Pidie Jaya merupakan kabupaten yang termasuk dalam lima besar produksi padi terbesar di Provinsi Aceh.

Tabel 1. Luas panen dan produksi padi tahun 2018-2019

\begin{tabular}{lccrrrr}
\hline & \multicolumn{2}{c}{ Luas panen (Ha) } & \multicolumn{2}{c}{$\begin{array}{c}\text { Produksi } \\
\text { (Ton-GKG) }\end{array}$} & \multicolumn{2}{c}{$\begin{array}{c}\text { Produksi } \\
\text { (Ton-Beras) }\end{array}$} \\
\cline { 2 - 7 } & \multicolumn{1}{c}{2018} & \multicolumn{1}{c}{2019} & \multicolumn{1}{c}{2018} & \multicolumn{1}{c}{2019} & 2018 & \multicolumn{1}{c}{2019} \\
\hline Aceh Besar & 39.224 & 32.884 & 232.541 & 187.597 & 133.273 & 107.515 \\
Pidie Jaya & 16.089 & 15.711 & 98.829 & 93.112 & 56.640 & 53.363 \\
Aceh & 329.516 & 310.012 & 1.861 .567 & 1.714 .438 & 1.066 .892 & 982.570 \\
\hline
\end{tabular}

Berdasarakan tabel 1. diatas, menunjukan bahwa luas panen padi (Ha), produksi padi (Ton-GKG), produksi beras (Ton-Beras) di Kabupaten Aceh Besar dan Kabupeten Pidie Jaya serta Provinsi Aceh mengalami penurunan pada tahun 2018-2019. Kabupaten Aceh Besar mengalami penurunan luas panen padi sebesar $6.340 \mathrm{Ha}$, produksi padi sebesar 44.944 TonGKG, produksi beras sebesar 25.758 Ton-Beras. Kabupaten Pidie Jaya juga mengalami penurunan luas panen padi sebesar $318 \mathrm{Ha}$, produksi padi sebesar 5.718 Ton-GKG, produksi beras sebesar 3.277 Ton-Beras. Provinsi Aceh juga mengalami penurunan luas panen padi sebesar 19.503 Ha, produksi padi sebesar 147.129 Ton-GKG, produksi beras sebesar 84.322 Ton-Beras.

Sikap adalah sebuah gambaran sistematis dalam pertimbangan mental dan emosional mengenai setuju atau tidak setuju terhadap sikap orang lain (Tankard et al., 2009). Toleransi adalah suatu sikap siap untuk menerima keadaan yang sedang dihadapinya, artinya adalah menerima perubahan dan perkembangan zaman dengan beberapa kelebihan yang akan diperoleh dan berbagai kekurangan yang akan melanda (Hariyanto, 2013). Perkembangan zaman juga dirasakan oleh petani padi sawah dengan hadirnya berbagai teknologi yang dikelompokkan dalam lima jenis penerapan teknologi usahatani padi sawah yaitu penerapan teknologi produksi dan pengolahan, penerapan teknologi peralatan, penerapan teknologi bangunan, penerapan teknologi lingkungan, dan penerapan teknologi penanganan hasil panen. Tanaman padi adalah tanaman pangan paling utama untuk masyarakat Aceh secara khusus dan masyarakat Indonesia secara umum, sehingga sangat perlu memerhatikan sikap toleransi dari petani padi sawah dan tingkat adopsi teknologi agar produksi tanaman padi tidak langka. Untuk mencegah hal tersebut, maka perlu diteliti seberapa toleran petani padi sawah yang dapat diukur melalui beberapa karakteristik seperti umur, jenis kelamin, pendidikan, luas lahan yang ditanami, usahatani warisan. Penelitian ini diharapkan mampu mengetahui teknologi apa saja yang telah digunakan petani padi sawah di Kabupaten Aceh Besar dan Kabupaten Pidie Jaya, dan mengetahui dan menganalisis bagaimana korelasi antara tingkat toleransi petani padi sawah dengan tingkat adopsi teknologi.

\section{METODE PENELITIAN}

\section{Tempat dan Waktu Penelitian}

Penelitian ini dilaksanakan di dua kabupaten yang terletak di Provinsi Aceh. Kedua kabupaten tersebut adalah Kabupaten Aceh Besar dan Kabupaten Pidie Jaya yang menjadi sentral produksi padi sawah di Provinsi Aceh. Kedua kabupaten tersebut adalah bagian dari lima besar kabupaten yang memproduksi padi sawah terbesar di Provinsi Aceh. Pemilihan tempat penelitian tersebut berdasarkan pada data Badan Pusat Statistik Aceh (BPS Aceh) dengan tujuan untuk melihat variasi adopsi teknologi yang digunakan petani padi sawah di 
Kabupaten Aceh Besar dan Kabupaten Pidie Jaya. Penelitian yang dilakukan di Kabupaten Aceh Besar terletak di Kecamatan Montasik, Kuta Baro, Darussalam. Penelitian yang dilakukan di Kabupaten Pidie Jaya terletak di Kecamatan Trienggadeng, Meureudu dan Bandar Baro. Penelitian ini akan dilaksanakan pada bulan April-Mei tahun 2021.

\section{Objek dan Ruang Lingkup Penelitian}

Objek dalam penelitian ini adalah petani padi sawah yang menggunakan teknologi di Kabupaten Aceh Besar dan Kabupaten Pidie Jaya. Ruang lingkup penelitian ini hanya berfokus pada sikap toleransi petani padi sawah dan tingkat adopsi teknologi padi.

\section{Populasi dan Sampel Penelitian}

Populasi dalam penelitian ini adalah petani padi sawah menggunakan teknologi di Kabupaten Aceh Besar dan Kabupaten Pidie Jaya. Teknik pengambilan sampel dalam penelitian ini menggunakan quota sampling yaitu salah satu ragam teknik pengambilan sampel nonprobabilitas dengan beberapa syarat karakteristik populasi tertentu untuk menentukan jumlah sampel yang diharapkan (Hikmawati, 2019). Pemilihan teknik pengambilan quota sampling dilakukan karena belum diketahui jelas dan tak terhingga jumlah populasi petani padi sawah yang menggunakan teknologi di Kabupaten Aceh Besar dan Kabupaten Pidie Jaya. Dengan teknik pengambilan quota sampling memberikan kebebasan kepada peneliti untuk menentukan ciri-ciri karakteristik sampel dan jumlah sampel yang akan diteliti. Selain itu, juga dapat meminimalisir biaya penelitian ke lapangan dan tidak memerlukan waktu yang lama dalam penelitian serta lebih mudah dari sudut pandang administratif (Moser, 2015). Penentuan sampel dalam penelitian ini adalah petani pemilik usahatani padi sawah yang menggunakan teknologi di Kabupaten Aceh Besar dan Kabupaten Pidie Jaya. Jumlah sampel dalam penelitian ini sebanyak 60 petani padi sawah atas pertimbangan bahwa 60 petani padi sawah tersebut dapat mewakili petani padi sawah yang mengadopsi teknologi di Kabupaten Aceh Besar dengan luas panen pada tahun 2020 sebesar 32. $821 \mathrm{Ha}$ dan di Kabupaten Pidie Jaya dengan luas panen pada tahun 2020 sebesar 15.884 Ha. Jumlah sampel tersebut dibagi dengan banyaknya kabupaten, sehingga masing-masing kabupaten sebanyak 30 petani padi sawah. Kedua kabupaten tersebut merupakan daerah yang telah mengadopsi teknologi, walaupun tidak representatif terhadap populasi. Metode ini diharapkan mampu mempresentasikan sikap toleransi petani padi sawah dan tingkat adopsi teknologi padi. Populasi pada penelitian ini bersifat homogen, dimana teknologi yang digunakan petani padi sawah cenderung sama. Metode pengumpulan data dalam penelitian ini menggunakan metode survei dengan kuesioner. Kuesioner tersebut berisi karakteristikkarakteristik responden yaitu: umur, jenis kelamin, pendidikan, luas lahan yang ditanami, usahatani warisan. Penelitian ini merupakan bagian dari penelitian terdahulu oleh Agussabti et al. (2020), dengan judul riset "Factors Affecting Risk Tolerance Among Small-Scale Seasonal Commodity Farmers and Strategies for Its Improvement".

\section{Jenis dan Pengumpulan Data}

Jenis data yang digunakan dalam penelitian ini adalah data primer dan sekunder. Pengumpulan data primer penelitian ini diperoleh melalui survei menggunakan kuesioner sedangkan pengumpulan data sekunder diperoleh dari BPS Aceh, BPTP Aceh dan berbagai karya ilmiah seperti jurnal, tesis dan skripsi.

\section{Metode Analisis Data}


Metode analisis yang digunakan dalam penelitian ini adalah analisis deskriptif dengan metode crosstabulasi. Analisis deskriptif adalah suatu metode yang digunakan untuk menginterprestasikan hasil penelitian dengan kalimat yang lebih ringkas dan mudah dimengerti. Tabulasi silang (Crosstabulation) adalah suatu metode analisis deskriptif dengan daya interprestasi yang baik untuk menerangkan korelasi antar variabel melalui penyebaran frekuensi dalam tabel sehingga mempermudah peneliti untuk melihat korelasi antar variabel. Untuk melakukan analisis data melalui metode analisis crosstabulasi ada beberapa ciri-ciri yang memudahkan peneliti untuk lebih paham dalam menggunakan metode tersebut antara lain: variabel yang digunakan dalam penelitian harus menggunakan dua atau lebih variabel, menyilangkan antar variabel, menggunakan data nominal atau data ordinal, hasil analisis dapat diinterprestasikan secara deskriptif (Ashari et al., 2017).

\section{HASIL DAN PEMBAHASAN}

\section{Penggunaan Teknologi Usahatani Padi Sawah}

Teknologi-teknologi usahatani padi sawah terdiri dari lima penerapan teknologi: yaitu penerapan teknologi produksi dan pengolahan terdiri dari 5 jenis teknologi, penerapan teknologi peralatan terdiri dari 8 jenis teknologi, penerapan teknologi bangunan terdiri dari 2 jenis teknologi, penerapan teknologi lingkungan terdiri dari 3 jenis teknologi dan penerapan teknologi penanganan hasil panen terdiri dari 4 jenis teknologi. Adapun masing-masing jenis penerapan teknologi adalah sebagi berikut: 
Tabel 2. Penerapan teknologi produksi dan pengolahan

\begin{tabular}{llrr}
\hline No & \multicolumn{1}{c}{ Jenis teknologi } & Jumlah petani & Persen $(\%)$ \\
\hline 1 & Bibit unggul & 52 & 87 \\
2 & Teknik budidaya & 32 & 53 \\
3 & Pestisida nabati & 17 & 28 \\
4 & Pengendalian hama terpadu & 17 & 28 \\
5 & Mina padi & 0 & 0 \\
\hline
\end{tabular}

Teknologi bibit unggul adalah teknologi yang paling banyak diadopsi oleh petani padi sawah di Kabupaten Aceh Besar dan Kabupaten Pidie Jaya yaitu sebanyak 52 dari 60 sampel petani padi sawah atau setara dengan $87 \%$. Hal ini disebabkan, karena bibit unggul adalah dasar penentu hasil panen padi. Ketika petani padi sawah menggunakan bibit unggul seperti ciherang, inpari, mekongga, dan jenis bibit unggul lainnya maka hasil panen yang diperoleh akan lebih berkualitas. Pemilihan sistem tanam tegel yang dilakukan oleh petani padi sawah di Kabupaten Aceh Besar dan Kabupaten Pidie Jaya disebabakan oleh perbedaan jumlah populasi padi dalam satuan hektar lahan. Teknik budidaya dengan sistem tanam tegel memerlukan lebih sedikit populasi padi dalam satu hektar lahan yakni sebesar 160.000 rumpun per hektar. Rendahnya penggunaan pestisida nabati atau yang dikenal dengan pestisida alami disebabkan karena maraknya distribusi pestisida buatan atau pestisida kimia. Pestisida nabati yang sering digunakan petani padi sawah di kedua kabupaten khususnya Kabupaten Aceh Besar adalah daun mimba. Minimnya pengguna teknologi pengendalian hama terpadu di kalangan petani padi sawah disebabkan karena mudahnya akses untuk membeli pertisida kimia dengan aplikasi yang praktis. Penerapan teknologi produksi dan pengolahan yaitu mina padi, merupakan perikanan dan pertanian dalam satu lahan sawah yang sama. Namun, petani padi sawah di Kabupaten Aceh Besar dan Kabupaten Pidie Jaya tidak mengadopsi teknologi mina padi pada lahan sawah karena masih enggan dan kurang paham dengan sistem teknologi mina padi.

Tabel 3. Penerapan teknologi peralatan

\begin{tabular}{clrr}
\hline No & \multicolumn{1}{c}{ Jenis teknologi } & Jumlah petani & Persen (\%) \\
\hline 1 & Traktor & 59 & 98 \\
2 & Rice transplanter & 1 & 2 \\
3 & Combine harvest & 47 & 78 \\
4 & Thresher & 11 & 18 \\
5 & Reaper & 9 & 15 \\
6 & ITGM & 1 & 2 \\
7 & Sprayer & 59 & 98 \\
8 & Gasrok & 4 & 7 \\
\hline
\end{tabular}

Dengan teknologi traktor, petani padi sawah hanya membutuhkan seorang pengemudi traktor saja sehingga dapat mengurangi biaya sewa ataupun upah buruh tani. Selain itu, penggunaan teknologi traktor sangatlah efektif dalam pengaplikasiannya. Cukup dengan satu atau dua hari, olah tanah I dan olah tanah II pada lahan siap untuk tahap selanjutnya. Penerapan teknologi peralaatan yaitu teknologi rice transplanter, merupakan teknologi peralatan yang memiliki beberapa syarat untuk layak pakai. Syarat tersebut antara lain adalah: benih disemai pada lahan yang sesuai ketetapan persemaian benih, lahan datar dan tekstur tanah pada lahan rata, lahan stabil dan tidak terlalu tergenang air, serta lahan yang luas. Selain itu, uang sewa atau upah sewa teknologi rice transplanter dan pengemudinya terbilang mahal 
sehingga petani padi sawah lebih memilih menanam padi secara manual dengan bantuan tenaga dari keluarganya. Dalam pengaplikasiannnya, combine harvest hanya membutuhkan satu pengemudi saja dan dua atau tiga orang pengumpul padi yang sudah bersih kemudian dimasukkan kedalam karung atau goni. Penggunaan teknologi thresher dilakukan secara bergantian dari satu lahan petani ke lahan petani yang lainnya (Bakar et al., 2020). Teknologi reaper berukuran besar dan dikendalikan oleh satu orang pengemudi yang terlatih. Cara pengaplikasian mesin ini sama halnya dengan traktor yaitu dengan cara mendorong teknologi tersebut. Namun, salah satu desa yang terletak di kecamatan Triengggading Kabupaten Pidie Jaya terdapat teknologi reaper yang tidak difungsikan lagi karena mesin yang rusak dan berkarat. Teknologi ITGM tidak berada langsung di lahan sawah melainkan disuatu gedung yang memiliki aliran listrik agar ITGM dapat dioperasikan. Jarak tempuh yang jauh dari rumah petani ke lokasi gudang tempat teknologi ITGM membuat petani lebih memilih alat yang lain seperti combine harvest. Teknologi sprayer memiliki beberapa kelebihan yang menjadi daya tarik bagi petani padi sawah yaitu: meringankan petani padi sawah dalam penyemprotan pestisida cair pada tanaman padi, sistem aplikasi yang sistematis serta sumber daya menggunakan baterai (diisi dengan daya listrik). Selain memiliki kelebihan, tentu saja juga memiliki kekurangan yaitu kapasitas penampungan atau wadah sprayer berukuran kecil sehingga harus diisi ulang setiap satu deplot habis. Teknologi gasrok masih jarang dikenal petani padi sawah dan kebanyakan sampel tidak mengetahui dan tidak mengenal teknologi gasrok. Kelangkaan penggunaan teknologi gasrok disebabkan karena kelangkaan distribusi teknologi gasrok di kedua kabupaten tersebut.

Tabel 4. Penerapan teknologi bangunan

\begin{tabular}{llrr}
\hline No & \multicolumn{1}{c}{ Jenis teknologi } & Jumlah petani & \multicolumn{2}{c}{ Persen (\%) } \\
\hline 1 & $\underline{\text { Sistem irigasi }}$ & $\underline{44}$ & $\underline{73}$ \\
2 & $\underline{\text { Embung }}$ & $\underline{6}$ & $\underline{10}$ \\
\hline
\end{tabular}

Pada umumnya petani padi sawah di Kabupaten Pidie membuat aliran air dari galingan susmur atau dari aliran sungai yang berada disekitaran sawah._Petani padi sawah yang berada di kabupaten Aceh Besar dominan menggunakan sistem irigasi yang berasal dari irigasi kreung Jreu yang berada di Kecamatan Indrapuri. Namun, air irigasi Krueng Jreu tidak selalu berjalan lancar disebabkan karena kekeringan pada saluran irigasi atau lain sebagainya (Bakar et al., 2020). Pada tahun 2019, terjadi kemarau panjang yang melanda Kabupaten Aceh Besar yang sangat merugikan petani padi sawah hingga mengalami puso atau kegagalan panen. Hal ini dialami oleh petani padi sawah yang berada di Desa Lambro Bileu Kecamatan Kuta Baro dan Desa Lam Ujung Kecamatan Darussalam. 
Tabel 5. Penerapan teknologi lingkungan

\begin{tabular}{llrr}
\hline No & \multicolumn{1}{c}{ Jenis teknologi } & Jumlah petani & Persen (\%) \\
\hline 1 & System of rice intenfication & $\underline{38}$ & $\underline{63}$ \\
2 & $\underline{\text { Konvensional }}$ & $\underline{3}$ & $\underline{\mathbf{3}}$ \\
3 & $\underline{\text { Rumah burung hantu }}$ & $\underline{27}$ \\
\hline
\end{tabular}

Pertanian dengan teknologi system of rice intenfication (SRI) merupakan suatu intenfikasi budidaya dengan bahan organik kompos yang berfungsi untuk mengurangi penggunaan pestisida kimia dan pestisida sintetis. Pertanian dengan teknologi konvensional merupakan pertanian atau budidaya padi yang dominan memakai pestisida seperti pestisida kimia dan pestisida sintetis. Rumah burung hantu hanya digunakan di Kabupaten Pidie Jaya walaupun tidak semua kecamatan yang mengadopsi teknologi tersebut.

Tabel 6. Penerapan teknologi penanganan pasca panen

\begin{tabular}{lcrr}
\hline No & Jenis teknologi & Jumlah petani & Persen (\%) \\
\hline 1 & Teknologi pengeringan & 0 & 0 \\
2 & Teknologi penggilingan & 60 & 100 \\
3 & Teknologi penyimpanan & 0 & 0 \\
4 & Teknologi packing & 0 & 0 \\
\hline
\end{tabular}

Umumnya, petani padi sawah padi di Provinsi Aceh masih menjemur padi dengan tenaga sinar matahari dan hanya menggunakan karung goni untuk packing dan disimpan dirumah atau digudang rumah.

\section{Adopsi Teknologi dan Toleransi Risiko}

Analisis tabulasi silang (Crosstabulation) adalah uji analisis yang digunakan untuk mengetahui dan menganalisis bagaimana korelasi antara tingkat toleransi petani terhadap risiko usahatani padi sawah dengan tingkat adopsi teknologi di Kabupaten Aceh Besar dan Kabupaten Pidie Jaya. tTngkat adopsi dikelompokkan menjadi tiga kategori yaitu rendah, sedang, dan tinggi. Tingkat adopsi teknologi dengan kategori rendah adalah tingkat adopsi teknologi yang hanya menerapkan dua teknologi saja yaitu penerapan teknologi produksi dan pengolahan, dan penerapan teknologi peralatan. Tingkat adopsi teknologi dengan kategori sedang adalah tingkat adopsi teknologi yang menerapkan tiga teknologi yaitu penerapan teknologi produksi dan pengolahan, penerapan teknologi peralatan, dan penerapan teknologi bangunan. Tingkat adopsi teknologi dengan kategori tinggi adalah tingkat adopsi teknologi yang menerapkan lima teknologi yaitu penerapan teknologi produksi dan pengolahan, penerapan teknologi peralatan, penerapan teknologi bangunan, penerapan teknologi lingkungan dan penerapan teknologi penanganan hasil panen. Seorang petani padi sawah hanya sampai mengadopsi penerapan teknologi peralatan maka diberi skor 1-2 dengan kategori rendah. Seorang petani padi sawah hanya sampai mengadopsi penerapan teknologi bangunan maka diberi skor 3 dengan kategori sedang. Seorang petani padi sawah yang mengadopsi kelima penerapan teknologi maka diberi skor 5 dengan kategori tinggi.

Tabel 7. Tabulasi silang tingkat adopsi dan tingkat toleransi

\begin{tabular}{lccrrrr}
\hline & & \multicolumn{3}{c}{ Tingkat toleransi } & \multirow{2}{*}{ Total } \\
\cline { 3 - 5 } & & Rendah & Sedang & Tinggi & \\
\hline Tingkat & Sedang & Jumlah & 1 & 4 & 1 & 6 \\
adopsi & & $(\%)$ & $16,7 \%$ & $66,7 \%$ & $16,7 \%$ & $100,0 \%$
\end{tabular}




\begin{tabular}{ccrrrr}
\multirow{2}{*}{ Tinggi } & Jumlah & 1 & 19 & 34 & 54 \\
& $(\%)$ & $1,9 \%$ & $35,2 \%$ & $63,0 \%$ & $100,0 \%$ \\
Total & Jumlah & 2 & 23 & 35 & 60 \\
\hline
\end{tabular}

Dari hasil tabel diatas, kedua variabel mempunyai korelasi positif, maka disimpulkan bahwa dengan meningkatnya tingkat toleransi petani padi sawah, maka secara otomatis juga meningkatkan penerapan teknologi pertanian padi sawah. Keberadaan tingkat adopsi paling banyak yang berada pada tingkat toleransi sedang disebabkan karena masih kurangnya penerapan teknologi lingkungan dan penerapan teknologi penanganan hasil panen, dimana petani padi sawah hanya mengadopsi teknologi produksi dan pengolahan, teknologi peralatan, dan teknologi bangunan.

\section{SIMPULAN DAN SARAN}

Berdasarkan data hasil penelitian diatas, maka diperoleh kesimpulan sebagai berikut: Teknologi-teknologi yang digunakan petani padi sawah di Kabupaten Aceh Besar dan Kabupaten Pidie Jaya adalah bibit unggul, teknik budidaya, pestisida nabati, pengendalian hama terpadu, traktor, rice transplanter, combine harvest, thresher, reaper, ITGM, sprayer, gasrok, sistem irigasi, embung, SRI, konvensional, rumah burung hantu, dan teknologi penggilingan. Diantara teknologi-teknologi tersebut, terdapat teknologi yang dominan dipakai oleh petani padi sawah yaitu: bibit unggul, traktor, sprayer, sistem irigasi, SRI, teknologi penggilingan. Terdapat korelasi antara tingkat adopsi teknologi dengan tingkat toleransi dengan arah positif.

Diharapkan pemerintah memberikan bantuan berupa penerapan teknologi bangunan seperti pembangunan irigasi dan embung di Kabupaten Aceh Besar dan Kabupaten Pidie Jaya. Diharapkan petani padi sawah yang berada di Kabupaten Aceh Besar dan Kabupaten Pidie Jaya dapat bertindak secara mandiri untuk membangun embung. Diharapkan pemerintah mendorong petani dengan jenis kelamin kategori laki-laki sebagai fokus utama untuk melakukan usahatani padi sawah. Diharapkan kepada penelitian selanjutnya untuk memerhatikan teknik pengambilan sampel dan variabel bebas yang lebih baik lagi. Diharapkan penelitian selanjutnya mengkaji pengaruh teknologi tertentu yang spesifik terhadap tingkat toleransi petani.

\section{DAFTAR PUSTAK}

Agussabti, A., R. Romano, R. Rahmaddiansyah and R. M. Isa. 2020. Factors Affecting Risk Tolerance among Small-Rasio Seasonal Commodity Farmers and Strategies for Its Improvement. Journal Heliyon. 6(12). https://doi.org/10.1016/j.heliyon.2020.e05847 Agustina, A. 2016. Pemodelan Faktor Risiko yang Berhubungan dengan Tingkat Keparahan Pelaku Kecelakaan Lalu Lintas Di Kabupaten Tuban Jawa Timur dengan Regresi Logistik Ordinal. Jurnal ilmiah Kesehatan Media Husada. 5(2): 120-121.

Ashari, B. H., B. M. Wibawa, and S. F. Persada. 2017. Analisis Deskriptif dan Tabulasi Silang pada Konsumen Online shop Di Instagram (Studi Kasus 6 Universitas di Kota Surabaya). Jurnal Sains Dan Seni ITS. 6(1): 17-21.

Badan Pusat Statistik Aceh. 2020. Pertanian, Kehutanan, Peternakan, dan Perikanan. Provinsi Aceh dalam Angka. < https://aceh.bps.go.id/> [Diakses tanggal: 11 Februari 2021]. 
Farizan, T. Fauzi, T. Makmur. 2018. Analisis Kelayakan Finansial Mesin Tanam Padi (Rice Transplanter) Di Desa Piyeung Aceh Besar. Jurnal Ilmiah Mahasiswa Pertanian Unsyiah. 3(2).

Laerd Statistics. 2018. Ordinal Regression using SPSS Statistics. [Online]: $<$ https://statistics.laerd.com/spss-tutorials/ordinal-regression-using-spssstatistics.php> [Diakses tanggal: 02 Juni 2021].

Pentury, T., S. N. Aulele, and R. Wattimena. 2016. Analisis Regresi Logistik Ordinal (Studi Kasus: Akreditas SMA Di Kota Ambon). Jurnal Ilmu Matematika dan Terapan. 10(1): 55-60. <https://doi.org/10.30598/barekengvol10iss1pp55-60>

Roe, B. E. 2015. The Risk Attitudes of U.S. Farmers. 37(4) : 553-574. https://doi.oroerg/10.1093/aepp/ppv022

Safrina. 2020. Sikap Petani terhadap Pengelolaan Irigasi Di Kecamatan Indrapuri Kabupaten Aceh Besar. Fakultas Pertanian Universitas Syiah Kuala, Banda Aceh.

Semesta Psikometrika. 2018. Cara Membuat Kategorisasi Data Penelitian dengan SPSS. [Online]: <https://www.semestapsikometrika.com/2018/07/membuat-kategori-skorrasio-dengan-spss.html $>$. [Diakses tanggal: 02 Juni 2021].

Wahyuni, W. 2018. Analisis Sikap Toleransi Petani Padi terhadap Risiko Usahatani Padi Di Aceh Besar, Pidie Jaya, dan Aceh Tengah. Fakultas Pertanian Universitas Syiah Kuala, Banda Aceh. 